https://doi.org/10.30843/nzpp.2019.72.321

\title{
Enhancing plant disease diagnostics in the Pacific
}

Katharina M. Hofer*, Merje Toome-Heller and Brett J.R. Alexander

Plant Health and Environment Laboratory, Ministry for Primary Industries (MPI), PO Box 2095, Auckland 1140, New Zealand

*Corresponding author: katharina.hofer@mpi.govt.nz

A project aiming to enhance biosecurity and market access in the Pacific was launched by NZ Aid in 2016. The project intends to benefit the economies of New Zealand's Pacific neighbours by improving their biosecurity systems which, in turn, would help to protect New Zealand's borders. Under the current project, the MPI's Plant Health and Environment Laboratory (PHEL) is accountable for delivering insect pest and disease diagnostic training in the Pacific and developing diagnostic tools. The PHEL Mycology and Bacteriology team has delivered a number of plant pathology training sessions in New Zealand, Cook Islands and Fiji. The main focus of the pathology module was to provide the Biosecurity Authority of Fiji (BAF) Plant Health Laboratory staff with skills and tools to conduct plant disease diagnostics at their facility. This included a full laboratory refurbishment and new molecular setup. As a result, the BAF team has become efficient with isolating and identifying plant pathogens using a combination of morphology and DNA-based approaches. They are now able to provide fast and sensitive testing for high impact diseases at the border or in future incursions. In addition to laboratory staff training, a number of quarantine officers were trained to enable them to recognise diseased plant material during import and export fresh produce inspections.

https://doi.org/10.30843/nzpp.2019.72.335

\section{Better biological control in glasshouses: synergies between biological control agents from different guilds and floral resources}

Emiliano R. Veronesi ${ }^{1 *}$, Oluwashola Olaniyan ${ }^{1}$, Stephen D. Wratten ${ }^{1}$, Melanie Davidson ${ }^{2}$ and Chris Thompson ${ }^{3}$

${ }^{1}$ Bio-Protection Research Centre, Lincoln University, PO Box 85084, Lincoln 7647, New Zealand

${ }^{2}$ The New Zealand Institute for Plant and Food Research Limited, Private Bag 4704, Christchurch Mail Centre, Christchurch 8140, New Zealand

${ }^{3}$ Bioforce Ltd, 72 Sim Road, Karaka, RD 1 Papakura 2580, New Zealand

*Corresponding author: emiliano.veronesi@lincolnuni.ac.nz

The tomato/potato psyllid (TPP), Bactericera cockerelli (Hemiptera, Triozidae), is an adventive psyllid in New Zealand that is a major pest of solanaceous crops and a serious threat to growers in the glasshouse industry. Worldwide, evaluation of potential biological control (BC) agents is normally conducted using single species and this is the case with some potential BC agents for TPP. However, the idea that multiple species can act synergistically remains largely untested so that is the aim of the current work, which is funded by Tomatoes New Zealand. The introduced parasitoid Tamarixia triozae is a BC agent of TPP that attacks mainly late instars. It lives for just 1 day when provided with water but can live up to 11 days (and consume more pests) when nectar in the flowers of buckwheat (Fagopyrum esculentum) is provided. In addition, another potential BC agent, the mirid bug Engytatus nicotianae, prefers young nymphal instars, while the ladybird Cleobora mellyi is voracious and consumes all instars. We are testing combinations of these species to understand the potential for synergies between and within trophic levels for better biological control. 